\title{
Strategic behaviour in a capacity market? The new Irish electricity market design
}

\author{
Juha Teirilä* Robert A. Ritz
}

December 2017

\begin{abstract}
The transition to a low-carbon power system requires growing the share of generation from (intermittent) renewables while ensuring security of supply. Policymakers and economists increasingly see a capacity mechanism as a way to deal with this challenge. Yet this raises new concerns about the exercise of market power by large players via the capacity auction. We present a new modelling approach that captures such strategic behaviour together with a set of ex ante empirical estimates for the new Irish electricity market design (I-SEM) - in which a single firm controls $44 \%$ of generation capacity (excluding wind). We find significant costs of strategic behaviour, even with new entry: In our baseline scenarios, procurement costs in the capacity auction are around 150-400 million EUR (or 40-100\%) above the competitive least-cost solution. From a policy perspective, we also examine how market power can be measured and mitigated through auction design.
\end{abstract}

Keywords: capacity market, strategic behaviour, competitive benchmark analysis, restructured electricity market, auction design

\section{Introduction}

Following several waves of merger activity since the 1990s, it is not uncommon for restructured electricity markets to be dominated by a small number of large players (Newbery (1995)). This has justified the use of regulatory price caps to protect consumers from the exercise of market power during periods of peak demand. Electricity markets now face the new challenge of responding to countries' ambitious decarbonization objectives (e.g.,

\footnotetext{
*Department of Economics, University Oulu, Finland. E-mail: juha.teirila@oulu.fi

$\dagger$ Judge Business School \& Energy Policy Research Group, University of Cambridge, UK. E-mail: rar36@cam.ac.uk
} 
IEA (2016)). This means growing (intermittent) renewables generation while ensuring security of supply is maintained during the energy transition.

It has recently been questioned whether an "energy-only" market can guarantee adequate generation. Wholesale price caps that are set too low can lead to a "missing money" problem (Cramton and Stoft (2006), Joskow (2008)), weakening investment incentives. Growing wind and solar generation can exacerbate the adequacy problem by decreasing the run-time of fossil-fuel generation. Uncertainty around government policy-e.g., renewables support mechanisms and the trajectory of carbon prices - is difficult to hedge and can drive up the cost of capital.

Policymakers and economists increasingly see a market design that combines an energy market with a capacity market as a way to deal with these challenges (e.g., Cramton and Stoft (2006), Joskow (2007), Cramton et al. (2013), Newbery (2016)). ${ }^{1}$ Capacity markets have in recent years been introduced in several European countries (e.g., Britain, France) and already exist in regional US markets (e.g., New England, PJM). They allow a government to procure its preferred level of resource adequacy at least cost via a competitive auction; winning generators commit to being available at a future date against an auction-determined capacity payment.

Our key observation is that the introduction of a capacity auction can give large incumbents an additional lever to exercise market power. Hence the outcome may depart from the least-cost solution - and be unfavourable for electricity consumers. Strategic behaviour can involve withholding capacity (to drive up the capacity payment received on remaining units) or predatory bidding (to induce rival exit from the electricity market). A player's incentive to exert market power in the capacity auction depends on competition in the electricity market, so these need to be modelled jointly.

In this paper, we present such a model with three components: (1) the electricity market (featuring a small number of strategic players and a competitive fringe), (2) the capacity auction and (3) industry dynamics, i.e., entry and exit decisions. We then present an empirical application to the new Irish Integrated Single Electricity Market (I-SEM), which is due to be implemented in 2018, and present a set of ex ante simulation results. $^{2}$

\footnotetext{
${ }^{1}$ Other potential solutions include a re-design of the electricity market (Hogan (2005), Roques (2008)) and a strategic reserve. Comparisons between different mechanisms are provided by de Vries (2004), Cramton and Stoft (2006), Finon and Pignon (2008) and Léautier (2016).

${ }^{2}$ The analysis in this paper is based on ex ante simulation of the potential for exercise of market power in the I-SEM design rather than ex post evaluation of actual firm behaviour. We do not suggest that any individual company violates or intends to violate any applicable competition law.
} 
The Irish case is interesting for four main reasons. First, a single firm ESB controls $44 \%$ of generation capacity (excluding wind farms) so concerns about strategic behaviour are already present. Second, the need to comply with the EU's Third Energy Package means that Ireland is moving from a system of administrative capacity payments to an auction; the committee responsible for the I-SEM's design noted that "The I-SEM capacity market is likely to exhibit structural market power, creating challenges for the design of the auction" (SEM Committee 2016, SEM-16-010, p. 23). Third, the Irish market is salient from a renewables perspective: fast-growing wind generation accounts for the bulk of new investment and over $20 \%$ of installed capacity in a system that has traditionally been dominated by ESB's gas-fired generation. Fourth, the I-SEM capacity market will be the first in Europe to feature a design based on reliability options (ROs). ${ }^{3}$

We quantify the impacts of strategic behaviour by ESB in the capacity market on wholesale prices and buyers' costs of purchasing electricity across a range of scenarios (e.g., different volumes of procured capacity, new entry). ${ }^{4}$ We find significant costs of strategic behaviour, even with new entry: In our baseline scenarios, procurement costs in the capacity auction are around 150-400 million EUR (or 40-100\%) above the competitive least-cost solution. From a policy perspective, we use the model to analyze the performance of well-known screening tools (e.g., RSI) in measuring market power in the capacity auction, and also explore how auction design can help mitigate market power. We find that using a differentiated bid cap for incumbents can partially mitigate market power-but also shifts significant informational requirements back onto the regulator.

Our paper contributes to the literature on market power in wholesale electricity markets (Green and Newbery (1992), Wolfram (1999), Sweeting (2007) on Great Britain; Borenstein et al. (2002), Joskow and Kahn (2002), Puller (2007), Mansur (2008) on US markets). This work mostly employs competitive benchmark analysis: it derives the competitive outcome via estimates of generators' unit costs and interprets any differences compared to the simulated equilibrium as evidence of strategic behaviour. We extend this

\footnotetext{
${ }^{3}$ The RO design was proposed by Vázquez et al. (2002), studied by Chao and Wilson (2004), Bidwell (2005), Oren (2005) and Cramton and Stoft (2008), and is already used in New England and Colombia. An RO is a financial contract that entitles the system operator (buyer) to receive a difference payment from a generator (seller) if the price in the electricity market exceeds a pre-defined strike price. Section 2 provides details.

${ }^{4}$ For reasons of computational feasibility, the empirical implementation of our model is restricted to strategic behaviour by a single firm (ESB) in the capacity auction. To be as realistic as possible, we allow the seven largest firms to have different degrees of market power in the electricity market. As a result, we think that our estimates of the costs of strategic behaviour are likely to be conservative (given that, in practice, multiple firms may have an incentive to behave strategically in the capacity auction).
} 
literature to the study of market power in the capacity market. We use a Cournot-based model of wholesale electricity market in which the degree of forward contracting serves as an index of competitiveness; higher contract cover pushes the equilibrium price down towards the perfectly competitive level (Allaz and Vila (1993)). ${ }^{5}$ A common form of vertical integration - pre-commitments to sell at a fixed retail price- has the same effect. We employ a similar approach to Bushnell et al. (2008), implemented as mixed integer linear programming (Ito and Reguant (2016)). ${ }^{6}$

Our work complements to two recent theoretical papers on capacity markets and market power. Schwenen (2014) uses a simple duopoly model to show how a non-competitive clearing price in a capacity auction "compensates" firms for a loss of market power in the electricity market. Léautier (2016) compares alternative capacity-market designs with a focus on investment incentives, and finds that ROs reduce market power but do not entirely eliminate it. Our analysis quantifies the impacts of strategic behaviour in an empirical context, and also speaks to its policy implications.

The paper is organized as follows. Section 2 summarizes the context of Irish electricity market design. Section 3 sets out our modelling approach, and Section 4 explains how we implement the model for the Irish case. Sections 5-7 contain our main analysis and results: (i) the two benchmarks of an energy-only market and competitive bidding in the capacity auction, (ii) the quantitative impacts of different forms of strategic behaviour in the capacity market, and (iii) policy options to measure and mitigate market power. Section 8 presents our conclusions.

\section{Electricity market design on the island of Ireland}

This section gives a brief overview of electricity generation on the island of Ireland, and then outlines the key features of the transition from the old to the new Irish market design (SEM and I-SEM).

Irish electricity generation. Table 1 summarizes the 2015 capacity and ownership structure. Total generation capacity amounts to just over 12 GW. Natural gas is the

\footnotetext{
${ }^{5}$ The intuition is that a higher degree of forward sales reduces the remaining share of sales in the spot market, thus reducing firms' incentives to affect that price.

${ }^{6}$ An alternative modelling approach uses the supply-function equilibrium (SFE) — see, e.g., Green and Newbery (1992), Wolfram (1999), Baldick and Hogan (2002). Its disadvantages in our setting include greater complexity and a greater potential for multiple equilibria. See Willems et al. (2009) for further discussion of the relative merits of SFE and Cournot-based models.
} 
Table 1: Registered nominal capacities (MW) (and number of generating units) of electricity generation firms in the SEM (by fuel type, excluding wind).

\begin{tabular}{|c|c|c|c|c|c|c|c|c|c|}
\hline Firm & Peat & Coal & Gas & Oil & Dist. & Hydro & Pump & Other & $(\%)$ \\
\hline ESB & $228(2)$ & $855(3)$ & $2625(11)$ & $53(1)$ & & $221(19)$ & $292(4)$ & $18(1)$ & 44.1 \\
\hline SSE & & & $464(1)$ & $588(4)$ & $208(4)$ & & & & 12.9 \\
\hline AES & & $476(2)$ & $510(3)$ & & $258(6)$ & & & & 12.8 \\
\hline Viridian & & & $764(2)$ & & & & & $6(1)$ & 7.9 \\
\hline NIE PP & & & $595(3)$ & & & & & $18(1)$ & 6.3 \\
\hline Bord Gais & & & $445(1)$ & & & & & & 4.6 \\
\hline Tynagh & & & $404(1)$ & & & & & & 4.1 \\
\hline other & $118(1)$ & & $12(1)$ & $169(3)$ & $188(3)$ & & & $215(8)$ & 7.3 \\
\hline Share (\%) & 3.6 & 13.7 & 59.8 & 8.3 & 6.7 & 2.3 & 3.0 & 2.7 & \\
\hline
\end{tabular}

Source: 'Registered Capacity Report July 2015' and 'List of Registered Units' by the SEMO.

main fuel, with a capacity share of close to $50 \%$; the second-largest fossil fuel is coal with a share of around 13\%. Wind power accounted for more than $20 \%$ of capacity. Generation from other sources such as peat, oil, distillates, and hydro pumps plays a more minor role; there is no nuclear power and negligible amounts of solar PV. ${ }^{7}$ The largest player ESB owns a substantial $44 \%$ of total capacity (excluding wind farms) while two other large firms, SSE and AES, control 14\% and 13\%, respectively. These three firms are the only ones that hold a diverse portfolio of generating units which uses different fuel inputs. Other players have small market shares and own only a small number of generating units. There are also two 500 MW cross-border interconnectors to the British electricity market: Moyle (between Scotland and Northern Ireland) and the East-West interconnector (EWIC, between Wales and the Republic of Ireland).

Single Electricity Market (SEM). The SEM was established in 2007 when jurisdictionally separate markets in the Republic of Ireland and Northern Ireland were combined. It is a gross mandatory pool in which the system operator calculates the least-cost dispatch schedule, resolves the System Marginal Price (SMP) for each trading period, and centrally dispatches units. $^{8}$ Generators also receive administrative capacity payments to cover their fixed costs; the regulator allocates these across trading periods and generating units. This centralized design is incompatible with the EU Third Energy Package's aim of fully integrating electricity markets according to market-based principles.

\footnotetext{
${ }^{7}$ Conventional generation as of January 2018 was mostly the same as in 2015 , with one new biomass unit and one fewer gas unit; the number of demand response units increased from 8 to 26 (215 MW to $433 \mathrm{MW}$ ) and wind power grew from $2504 \mathrm{MW}$ to $3751 \mathrm{MW}$.

${ }^{8}$ The SMP is the sum of two components: (i) a shadow price that reflects the short-run cost of the marginal producer, and (ii) an uplift that indicates the amount which may be needed to cover start-up and no-load costs (if the infra-marginal rent is not enough to cover these).
} 
Integrated Single Electricity Market (I-SEM). The new I-SEM market design will differ from the SEM by: (1) introducing forward, day-ahead, intraday, and balancing markets, which are cleared before the physical delivery takes place; (2) implementing a new cross-border power flow algorithm; and (3) replacing the administrative capacity mechanism with a market-based capacity auction. The third change is the motivation for our analysis. ${ }^{9}$

The new capacity market will be based on auctioned reliability options (ROs). The system operator (SO) purchases ROs from the capacity providers. An RO is a financial contract that entitles the SO (buyer) to receive a difference payment from a generator (seller) if the price in the electricity market exceeds a pre-defined strike price. ROs are backed by physical generation capacity; the SO thus pays the generators an auctiondetermined price for the sale of an option - a kind of market-based capacity payment. ${ }^{10}$ ROs will be sold in an annual uniform price auction. The SO determines the amount of capacity needed for supply security; then it holds an auction to purchase ROs that cover this capacity. Under current plans, the auction takes place 4 years before delivery (T-4); there will also be shorter-term (T-1) auctions. In an auction, generators submit a price bid for each of their units; this defines the price at which an RO backed by a unit's generation capacity is offered. ${ }^{11}$ All existing units and new units that are credibly available by the delivery year are eligible to bid; participation is mandatory for all existing dispatchable units with at least $10 \mathrm{MW}$ capacity. The auction clears at the minimum price $(\mathrm{EUR} / \mathrm{kW})$ that procures the desired RO capacity. Generators that have bid no more than this clearing price receive a capacity payment based on their winning capacity. In turn, generators make a difference payment to the SO in trading periods where the electricity market price exceeds a pre-defined strike price. This difference payment equals the spread between the market price and strike price times the generators' RO capacity sales.

With all generation capacity in a market sold as ROs, the strike price effectively sets a price cap in the electricity market, thus fully hedging electricity buyers against higher prices. In effect, a generator selling ROs concedes some peak-load profits in exchange for

\footnotetext{
${ }^{9}$ Under current plans, I-SEM will be implemented during 2018 . The energy market should commence in May 2018, the first T-1 auction is scheduled to take place in December 2017 with a delivery period of May 2018-September 2019; the first T-4 auction is planned for the end of 2018. See di Cosmo and Lynch (2015) for a valuable discussion of competition issues in wholesale and retail markets under the new I-SEM design.

${ }^{10}$ As holder of the ROs, the SO has the right but not the obligation to buy electricity at a strike price-thus, the term reliability option.

${ }^{11}$ Specifically, each unit can submit a bid curve with a maximum of five incremental steps.
} 
the capacity payment. Generators that do not sell ROs do not need to pay the difference payment and do not receive the capacity payment-but they can still operate normally in the electricity market.

\section{The model}

The model has three stages. First, firms sell capacity-backed reliability options (ROs) in the capacity market. Second, firms decide which generating units stay active and if any new units are built. Third, firms compete in the electricity market. A firm's behaviour in an individual stage thus depends on its profits in the following stage(s). We now describe the three stages in reverse order, and then summarize the properties of the overall equilibrium.

$3^{\text {rd }}$ stage: Electricity market. The time interval is hourly, denoted by $h \in\{1, \ldots, 8760\}$. Total electricity demand $D_{h}^{\text {total }}$ varies across hours. Available generation units have been determined by the first two stages. Strategic firms $i \in\{1, \ldots, N\}$, operating a portfolio of units $j \in\left\{1, \ldots, J_{i}\right\}$, can exercise market power by bidding above their marginal cost. Supply $S_{h}^{\text {exog }}$ is exogenous, for example, that of wind farms or must-run units. A fringe of smaller firms act as competitive price-takers, bidding their true marginal cost; their supply $S^{\text {fringe }}\left(p_{h}\right)$ depends on the hourly wholesale price $p_{h}$. The residual demand function faced by the strategic firms is thus: $D_{h}\left(p_{h}\right)=D_{h}^{\text {total }}-S_{h}^{\text {exog }}-S^{\text {fringe }}\left(p_{h}\right)$. Fringe supply makes this residual demand price-elastic.

Strategic firms compete à la Cournot: each chooses how much electricity to produce in each hour, taking other firms' production as given. Firm $i$ 's short-run electricity-market profit (excluding fixed costs and capacity payments) in period $h$ is:

$$
\pi_{i h}=P_{h}\left(Q_{h}\right)\left(q_{i h}-q_{i h}^{f}\right)+p^{f} q_{i h}^{f}-V C_{i h}\left(q_{i h}\right)-D P_{i h}\left(Q_{h}\right)
$$

Firm $i$ 's electricity generation is $q_{i h} \leq K_{i h}$, where $K_{i h}$ is its available capacity, and $P_{h}\left(Q_{h}\right) \equiv D_{h}^{-1}\left(Q_{h}\right)$ is the inverse of residual demand, where $Q_{h} \equiv \sum_{r=1}^{N} q_{r h}$ is total generation by strategic firms. Firm $i$ also delivers $q_{i h}^{f}$ of electricity which is sold forward months or years earlier at a forward price $p^{f} .{ }^{12}$ Firm's variable cost of generation is

\footnotetext{
${ }^{12}$ In our model, forward sales are exogenous and their share of total sales is constant across hours; following Bushnell et al. (2008), $q_{i h}^{f}$ can also be interpreted as a fixed-price retail commitment. More generally, there could be interactions with the introduction of a capacity market. For example, it may "crowd out" liquidity from the forward market which, in turn, could make the electricity market less
} 
$V C_{i h}(\cdot)$, and it makes a difference payment defined as:

$$
D P_{i h}\left(Q_{h}\right)=\max \left\{\left(P_{h}\left(Q_{h}\right)-p^{\text {strike }}\right) \times k_{i}, \quad 0\right\}
$$

where $p^{\text {strike }}$ is the strike price of ROs procured in the capacity market, and $k_{i}$ is the amount of capacity needed to back the ROs sold by firm $i$.

So $i$ 's first-order condition for an interior solution $\left(0<q_{i h}<K_{i h}\right)$ is:

$$
\frac{\partial P_{h}\left(Q_{h}\right)}{\partial q_{i h}}\left[q_{i h}-q_{i h}^{f}-\mathbb{1}\left(P_{h}\left(Q_{h}\right)>p^{\text {strike }}\right) k_{i}\right]+\left[P_{h}\left(Q_{h}\right)-M C_{i h}\left(q_{i h}\right)\right]=0,
$$

where $M C_{i h}\left(q_{i h}\right) \equiv \frac{\partial V C_{i h}\left(q_{i h}\right)}{\partial q_{i h}}$ is marginal cost and $\mathbb{1}(\cdot)$ is an indicator function, which equals one if the market price exceeds the strike price. The left-hand term captures the mark-up over the competitive price due to strategic behaviour. All else equal, this markup decreases with more forward sales $q_{i h}^{f}$. Also, if the market price exceeds the strike price, the mark-up decreases with more capacity sold as ROs $k_{i}$. (Otherwise, the solution is at a boundary, with $q_{i h}=0$ or $q_{i h}=K_{i h}$.)

Marginal cost $M C_{i h}(q)$ is a horizontal aggregate of the marginal-cost functions of the units owned by firm $i$. It varies across hours as all units are not always available. The marginal cost function of a single generating unit is an increasing step function that has one or more steps. ${ }^{13}$ Variable cost $V C_{i h}(q)$ is then a continuous increasing piecewise-linear function that consists of linear segments with increasing slopes. ${ }^{14}$

The competitive fringe generates electricity with all capacity that has marginal cost below the current spot price $p_{h}$, so that $S^{\text {fringe }}\left(p_{h}\right)=M C_{\text {fringe }}^{-1}\left(p_{h}\right)$, where the latter is the inverse of the fringe firms' aggregated marginal cost (step) function.

Let $\hat{q}_{i h}\left(q_{-i, h}\right)$ denote $i$ 's best response from (3) to rivals combined output $q_{-i, h}$. In Cournot equilibrium, firm $i$ 's annual maximized short-run profit from the electricity mar-

competitive (all else equal). Another possibility is that the capacity market induces a change to the generation mix, and this also alters the overall degree of contract cover. Modelling such interactions is beyond our scope but this is an interesting avenue for future research.

${ }^{13}$ To always find a unique solution in the simulations, the original marginal cost step functions are altered a little to make them strictly increasing. Specifically, for each horizontal part, a 0.01 EUR increase in price is assumed and, for each vertical part, a $1 \mathrm{MW}$ increase in capacity is assumed.

${ }^{14}$ In practice, firms also face dynamic costs and restrictions (e.g., minimum load, start-up costs, ramping rate) when generating electricity; these are not included in the model as they would increase the computation time enormously. 
ket is therefore:

$$
\hat{\pi}_{i}^{S R}=\sum_{h=1}^{8760} \max _{q_{i h}} \pi_{i h}\left[\hat{q}_{i h}\left(\hat{q}_{-i, h}\right), \hat{q}_{-i, h}\left(\hat{q}_{i h}\right)\right] .
$$

This stage generally has a unique solution - except possibly in the case where the strike price binds. ${ }^{15}$

$2^{\text {nd }}$ stage: Entry and exit. In the second stage, firms make binary decisions on which of their incumbent units remain active - and which potential new units are built. These take as given the outcome of the capacity auction in the first stage: the unit price of capacity $p^{c p}$ and the generating units that won in the auction. Let $w_{i j}=1$ if firm $i$ 's unit $j$ has won the capacity payment, and otherwise $w_{i j}=0$. Let $a_{i j}=1$ denote active units that are available to generate, and denote inactive units that have been closed or not built as $a_{i j}=0$. Winning units in the auction are committed to be active (i.e., $w_{i j}=1 \Rightarrow a_{i j}=1$ ) while units that do not win in the capacity auction can still operate in the electricity market. ${ }^{16}$ Let the vector $a_{i} \equiv\left(a_{i j}\right)_{j=1}^{J_{i}}$ collect the activity levels of all units owned by $i$

Strategic firm $i$ 's optimization problem is to choose $a_{i}$ to maximize its long-run profits, given other firms' decisions $a_{-i}$, so that:

$$
\hat{\pi}_{i}^{L R}=\max _{a_{i}}\left\{\hat{\pi}_{i}^{S R}\left(a_{i}, a_{-i}\right)-\sum_{j=1}^{J_{i}} a_{i j} F C_{i j}+p^{c p} k_{i}\right\}
$$

where $F C_{i j}$ is the fixed cost of its $j^{\text {th }}$ unit (which accrues only if this unit is active) ${ }^{17}, k_{i}$ is its winning capacity from the auction, and $p^{c p} k_{i}$ is its capacity payments. Observe that firms' decisions in this second stage will affect short-run profits $\hat{\pi}_{i}^{S R}$ in the third stage as these will depend on all active units in the electricity market, that is, $a_{i j} \forall i, j$. Fringe firms also choose their active units to maximize their long-run profits. Unlike strategic

\footnotetext{
${ }^{15}$ There may be hours for which (3) is not satisfied when $P_{h}\left(Q_{h}\right) \leq p^{\text {strike }}$ or when $P_{h}\left(Q_{h}\right)>p^{\text {strike }}$. In these hours, the market price settles to the strike price-but there is an infinite number of bestresponse production combinations that result in this market price. We resolve this multiple equilibria issue by selecting a vector of production quantities that is on the line connecting the equilibria of the two unconstrained first-order conditions. See the literature on Cournot competition with a price cap for details (e.g., Buehler et al. (2010)).

${ }^{16}$ Strategic behaviour in the capacity market affects the final generating portfolio via this commitment.

${ }^{17}$ We treat the investment cost for a new generation unit as a fixed cost which is split across the unit's lifetime; hence, all else equal, the fixed cost $F C_{i j}$ is higher for new units than for existing units. Exit costs, arising from the decommissioning of units, are omitted in the modeling because of limited available information across different types of generation.
} 
firms, they cannot make commitments in the capacity market to keep loss-making units active.

In equilibrium, no strategic or fringe firm can increase its long-run profits by: (i) closing an active unit that does not receive a capacity payment, or (ii) entering the market with a new-build unit. This stage potentially has multiple equilibria - as is well-known from the industrial-organization literature on entry models, see, e.g., Einav (2010). ${ }^{18}$ We resolve this potential multiplicity by assuming that, starting from the existing generator portfolio, entry/exit decisions happen one unit at a time: the incumbent unit with highest losses is closed first and the potential entrant with the highest post-entry profits enters first. ${ }^{19}$ For fringe firms, this always leads to an efficient portfolio. However, the overall generation portfolio can deviate from the efficient outcome since the strategic firms can affect the entry and exit process by their behaviour in the capacity market.

$\mathbf{1}^{\text {st }}$ stage: Capacity market. Existing units as well as potential new-build units participate in an annual capacity market, modelled as a descending-clock auction. To begin, to-be-procured capacity $\bar{K}$ and the difference-payment strike price $p^{\text {strike }}$ are announced. In the first auction round $(r=1)$, the auction price $p_{r}^{c p}$ is set to equal the bid cap. Each firm decides for each of its generating units whether the unit stays in the auction or quits. If there is more capacity left bidding than $\bar{K}$, then auction proceeds to the next round - and the price is decreased by one step, $p_{r+1}^{c p}=p_{r}^{c p}-\Delta p^{c p}$. The auction ends when the bidding capacity drops below $\bar{K}$ (or the price reaches zero).

Formally, denote the exit price for firm $i$ 's unit $j$ as $b_{i j}$; if the auction price drops below this price, this unit quits the auction. The auction stops at round $\widehat{r}$ if the (derated) capacity in the auction then falls below the target capacity:

$$
\sum_{i, j} \mathbb{1}\left(b_{i j} \leq p_{\widehat{r}}^{c p}\right) \delta_{i j} K_{i j} \leq \bar{K}<\sum_{i, j} \mathbb{1}\left(b_{i j} \leq p_{\widehat{r}-1}^{c p}\right) \delta_{i j} K_{i j}
$$

where $\delta_{i j}$ is a technology- and size-specific de-rating factor, and $K_{i j}$ is the unit's nominal capacity. Then the clearing price $p^{c p}=p_{\widehat{r}}^{c p}$ and the winning units $w_{i j}=\mathbb{1}\left(b_{i j} \leq p_{\widehat{r}}^{c p}\right)$. The committed capacity used as the basis for the firm's difference payment $D P_{i h}\left(Q_{h}\right)$, see

\footnotetext{
${ }^{18}$ To illustrate, consider two units $A$ and $B$. It is possible that both units are unprofitable if both are active in the market, $A$ becomes profitable if $B$ exits and similarly $B$ becomes profitable if $A$ exits. A rule on move order is needed to resolve this multiplicity.

${ }^{19}$ These decisions are myopic in that they do not factor in future entry/exit decisions of rivals. Another modelling assumption could be that the loss-making unit of a smaller firm exits first and that a larger firm enters first. This may lead to a more concentrated final generation portfolio, particularly when the electricity market is very competitive.
} 
(2), and capacity payment $p^{c p} k_{i}$ is: $k_{i}=\sum_{j=1}^{J_{i}} w_{i j} \delta_{i j} K_{i j}$. Strategic firm $i$ 's optimization problem is to choose a bid vector $b_{i} \equiv\left(b_{i j}\right)_{j=1}^{J_{i}}$ that, given other firms' bids $b_{-i}$, maximizes its long-run profits that result from the entry and exit process of the second stage:

$$
\max _{b_{i}}\left\{\hat{\pi}_{i}^{L R}\left(b_{i}, b_{-i}\right)\right\}
$$

Fringe firms simply bid the price that each generation unit needs to break even in terms of its long-term profits, given the other units in the market - or they bid zero if the unit is already profitable. ${ }^{20}$

This stage also may have multiple equilibria. Our empirical application below resolves this by restricting attention to market power exerted by a single large strategic firm. Finally, we make an assumption that reduces the action space for strategic firms: In the capacity auction, strategic firms choose increasing bid curves such that their units are always in the same order. That is, even if individual bids change, the same unit is always assigned the highest bid, and the same unit always has the second-highest bid, and so on. Hence the order of units is the same as in the competitive benchmark. ${ }^{21}$ (Note that this assumption holds only for individual firms, not for the aggregated bid curve.)

Equilibrium. The three stages of the model are nested: the objective function of a strategic firm in each stage contains the solution of the maximization problem in the following stage. The overall equilibrium occurs where none of the strategic firms wishes to unilaterally change its behaviour in any stage. See Appendix A for a visual description of firms' decision flow and the model equilibrium.

Our analysis will focus on the annual total costs for electricity buyers which arise,

\footnotetext{
${ }^{20}$ This is conceptually equivalent to how competitive units behave in the electricity market: they bid their static marginal costs, and units bid lower than the marginal unit are dispatched. An important difference is that, in the capacity market, competitive units' profits and, therefore, their bids also depend on the total active generation portfolio in the market.

${ }^{21}$ Our approach is similar to that used in Sweeting (2007), where different strategies adopted by an individual firm in the electricity market are compared by multiplying the price bids for all of its units by the same coefficient. To illustrate the issue, consider a firm with 14 units in the auction which has $P$ price levels $\left(p_{1}^{c p}, p_{2}^{c p}, \ldots, 0\right)$. If these units can be in any order in the bid curve, there are $P^{14}$ possible bid combinations. In a uniform price auction it is enough to know, whether an individual bid sets the price, or is above or below the clearing price. Still, there is a large number of combinations, which units bid above and which below the clearing price. Under our assumption, there are 15 possible actions for each auction price level $p_{r}^{c p}$ : all units bid higher than the auction price; unit 1 bids lower and others higher; unit 1 and unit 2 bid lower and others higher; and so on. Thus, the firm has $P \times 15$ different actions to choose from. It seems plausible that more efficient units bid lower in practice- such that a firm increases the likelihood of its best units staying in the market.
} 
respectively, from the electricity and capacity markets:

$$
\begin{aligned}
\text { total buyer cost in electricity market } & =\sum_{h=1}^{8760}\left[p_{h}\left(Q_{h}-Q_{h}^{f}\right)+p^{f} Q_{h}^{f}\right] \\
\text { total buyer cost in capacity market } & =p^{c p} \sum_{i, j} w_{i j} \delta_{i j} K_{i j},
\end{aligned}
$$

where $p^{f}$ is the average price over the year and $Q_{h}^{f}$ is the amount sold forward by all firms together at hour $h$. In the absence of detailed information on buyers' willingness-to-pay for supply security, we view total costs across the electricity and capacity markets as a proxy for consumer welfare

\section{Implementing the model for the Irish market}

\subsection{Using information from the SEM design}

The model is calibrated using 2015 data from the Irish SEM. ${ }^{22}$ The two main data sources are EirGrid for data on the status of the Irish power system, ${ }^{23}$ and the SEMO for detailed trading data such as bids, prices, payments, and generation quantities. ${ }^{24}$

Demand, exogenous supply, and prices. We use system demand reported by EirGrid to obtain the hourly total demand for electricity. EirGrid also publishes an estimate of total output of all wind farms in the system. To account for the supply and demand by pumped hydro storages, we use these units' metered generation data as published by the SEMO. This reveals a fairly regular diurnal pattern: pumped storages run at nighttime and generate electricity at daytime, independently of the electricity price. Net imports into Ireland are driven mainly by variation in demand and wind farm production. When total demand net of wind energy is high, more electricity is imported from Great Britain, and vice versa. Moreover, the correlation between hourly interconnector load and the price difference between the SEM and the British electricity market is weak. ${ }^{25}$ This suggests that market participants use interconnectors primarily to hedge their generation

\footnotetext{
${ }^{22}$ See Appendix A for further details on the computational implementation of the model.

${ }^{23}$ See www.eirgridgroup.com $\rightarrow$ How the Grid Works $\rightarrow$ System Information.

${ }^{24}$ See www.sem-o.com $\rightarrow$ Market Data $\rightarrow$ Dynamic Reports, and www.sem-o.com $\rightarrow$ Publications $\rightarrow$ General Publications.

${ }^{25}$ Specifically, the correlation coefficient between the price difference (SMP vs N2EX day-ahead price) and the interconnector load is only 0.14 (using 2015 data).
} 
portfolios against demand fluctuations in the domestic market (rather than for price arbitrage). Therefore, we consider supply from wind farms, pumped hydro storages and interconnectors as exogenous. Finally, we use the SEMO's half-hourly data on realized electricity prices (SMP and shadow price).

Generating units and ownership. We combine generator data from the 'Registered Capacity Report' from July 2015 and plant ownership data from the 'List of Registered Units' published by the SEMO. For units that report using multiple types of fuel, we determine their main fuel source by drawing on other data sources such as firms' websites. The SEM classifies all registered units either as price makers or price takers. Price makers are units that are dispatched based on the market price while price takers take the market price as given. We consider all units defined as price takers and price-making hydro units (which typically bid zero) as must-run units. These units include all peat, hydro, biomass, and waste units. There are also a few price-taking oil and gas units serving industrial processes: two oil units (in an alumina refinery) and one gas unit (CHP in an industrial bottling plant), which run very steadily so we consider them as must-run. This leaves 55 price-making units of coal, gas, oil, distillate, and demand response that effectively set the half-hourly price in the SEM.

Bidding and marginal costs. The SEM bidding code obliges firms to bid their true short-run marginal costs, so we assume that observed bids truthfully reveal each unit's costs. These bids are publicly available on the SEM website for each unit and half-hourly trading period. A bid for a single unit consists of at most 10 price-quantity pairs; typically, firms use only 1-4 pairs. Firms' bids vary slightly between days over the year, mostly due to changes in fuel and carbon prices. ${ }^{26}$ To simplify calculations, we use a representative bid curve for each unit for all hours; specifically, we select a day that represents the unit's median bid submitted over the year.

Capacity payments and fixed costs. In the SEM, the regulatory authority determines the total amount of capacity payments for a specific year by using two estimates: (1) the annualized fixed costs of a best new entrant peaking plant, and (2) the amount of capacity required to guarantee the security of supply. For 2015, the annualized fixed cost for the

\footnotetext{
${ }^{26}$ Irish electricity generators have been part of the EU's Emissions Trading Scheme (EU ETS) since 2005, and therefore need to hold sufficient permits to cover their carbon emissions. These carbon costs are part of a unit's short-run marginal costs. The 2015 year-average EU ETS price was approximately EUR $7.50 / \mathrm{tCO}_{2}$; the price near the end of 2017 was similarly around EUR $7 / \mathrm{tCO}_{2}$.
} 
reference plant was estimated to be $91.88 \mathrm{EUR} / \mathrm{kW} /$ year. ${ }^{27}$ Adjusting for revenue from ancillary services (4.53 EUR/kW/year) and infra-marginal rent $(5.75 \mathrm{EUR} / \mathrm{kW} /$ year, received when capacity is scarce and the marginal plant bids the price cap), the amount used as a basis for the capacity payment was $81.60 \mathrm{EUR} / \mathrm{kW} /$ year. $^{28}$ Finally, the estimated amount of required capacity was $7046 \mathrm{MW} .^{29}$ In 2015 , total generating capacity was higher than required, so the capacity payments received by existing units were less than the estimated fixed cost. Using SEMO data (Dynamic Reports $\rightarrow$ Capacity Payments by Unit), we calculate that the average capacity payment for gas, oil, and distillate units in 2015 was $54.50 \mathrm{EUR} / \mathrm{kW} /$ year. Since this was the only revenue made by several units in the market, we take this as the fixed cost for all existing gas, oil, and distillate units. The fixed costs of coal units are typically higher; we assume that their fixed costs are fully covered by the average capacity payment and the infra-marginal rent. For the five coal units, this was $119.01 \mathrm{EUR} / \mathrm{kW} /$ year in 2015.

Availability and de-rating factors. We use Monte Carlo simulation based on SEMO data to account for forced outages and scheduled maintenance as well as for de-rating factors in the capacity auction. ${ }^{30}$

\subsection{Modelling the new I-SEM design}

Strategic players. For the electricity market, we assume that the seven largest firms by capacity (ESB, SSE, AES, Viridian, NIE PP, Bord Gais, Tynagh) behave strategically, while the other eight smaller firms form a competitive fringe. The strategic firms own a

\footnotetext{
${ }^{27}$ For the years 2013-2015, the reference plant was a hypothetical 196.5 MW plant with an Alstom GT13E2 turbine, located in Northern Ireland, using distillate as a fuel, with a 20-year lifetime and a forced outage probability of $5.91 \%$.

${ }^{28}$ We also use these figures to estimate that profits from ancillary services are around $2 \%$ of total profits for a typical generating unit.

${ }^{29}$ See 'SEM-14-070: Decision Paper on Capacity Requirement and Annual Capacity Payment Sum for Calendar Year 2015' for the capacity payment decisions and 'SEM-12-078: Decision Paper on BNE Peaker for 2013' for the detailed cost breakdown for the best new entrant plant. Both documents can be found at ww. semcommittee.com $\rightarrow$ Publications.

30 'SEM-16-051a: Capacity Remuneration Mechanism: Proposed Methodology for the Calculation of the Capacity Requirement and De-rating Factors' is available at www . semcommittee.com $\rightarrow$ Publications. We use the information in Table 3 (outages \& maintenance) and Table 4 (de-rating factors). For gas units, there is a $3.6 \%$ probability of forced outage; for coal, oil, and distillate units it is $7.2 \%$. Occasional non-availability of generating units is taken into account by de-rating the nominal capacity of each unit in the capacity-auction bids so that each unit's actual contribution to procured capacity is less than its nominal capacity. For gas turbines, the de-rating factors vary from $91.1 \%$ to $95.8 \%$ while they vary from $83.1 \%$ to $91.8 \%$ for coal, oil, and distillate units.
} 
total of 41 generating units. ${ }^{31}$ The literature on wholesale electricity markets commonly assumes that only larger firms behave strategically while smaller players bid competitively, and there is empirical evidence to support this difference in bidding behaviour according to firm size (e.g., Hortaçsu and Puller (2008)). For the capacity market, we assume that ESB can behave strategically while all other firms bid competitively; this is because the computation time of the model simulations otherwise becomes unworkable.

Forward contracting in the electricity market. The competitiveness of the electricity market in the I-SEM is not yet known. Our analysis therefore presents results for different levels of forward contracting, ranging from zero forward sales (which leads to the standard Cournot-Nash equilibrium) to $100 \%$ forward sales (which corresponds to perfect competition). We place a particular focus on $60-80 \%$ contract cover given that this (i) is consistent with estimates of market competitiveness in the extant literature on competition in wholesale electricity markets, and (ii) reflects real-world practice in other European countries. ${ }^{32}$

Procured volume in the capacity market. We obtain simulation results for volumes of procured capacity within the range of 4000-7500 MW. Note that these volumes refer only to capacity procured from the 41 units owned by the strategic players. For comparison, maximum demand in the 2015 SEM was $6397 \mathrm{MW}$, and realized demand net of wind production varied from zero to $6074 \mathrm{MW}$. Given that there currently is excess capacity in Ireland, it seems likely that the I-SEM will procure somewhat less than currently existing capacity (see Table 1). Indeed, the first I-SEM capacity auction in December 2017 stands to procure $7030 \mathrm{MW}$ of (de-rated) capacity. ${ }^{33}$ Of this, around $1000 \mathrm{MW}$ comes from must-run units, pumped hydro, wind farms ${ }^{34}$ and interconnectors - which are not included in the capacity volumes reported in our modelling. Hence this first procurement volume corresponds to around $6000 \mathrm{MW}$ in our numbers. ${ }^{35}$ Procurement volumes far

\footnotetext{
${ }^{31}$ The total capacity of the competitive fringe $(418 \mathrm{MW})$ is small relative to the strategic players $(8129$ $\mathrm{MW}$ ), and its units have relatively high marginal costs. These consist of one $12 \mathrm{MW}$ gas unit, one $3 \mathrm{MW}$ oil unit, 3 distillate units (total $188 \mathrm{MW}$ ), and 8 demand response units (total $215 \mathrm{MW}$ ). (Note that must-run units are not included here as they are exogenous in the model whereas table 1 lists all units.)

${ }^{32}$ ECA (2015) provide a useful overview of forward-contracting products and practices in Europe; see also Anderson et al. (2007) and Ritz (2016) for related empirical evidence and analysis.

${ }^{33}$ The detailed parameters of the first auction can be found in 'Final Auction Information Pack v1.0.pdf' in www.sem-o.com $\rightarrow$ I-SEM $\rightarrow$ Publications.

${ }^{34}$ Wind power is de-rated strongly in the capacity auction (in the first auction the de-rating factor was 0.103). Therefore, even if wind power capacity is large in Ireland and increasing rapidly, wind farms are not significant players in the capacity market.

${ }^{35}$ Comparing at a later date our ex ante results with ex post I-SEM market outcomes may thus require
} 
away from 6000 MW may currently seem unlikely but it will be useful to understand the market-power implications of (i) having no idle units as in an energy-only market, and (ii) procured capacity approaching existing capacity.

Bid cap and RO strike price in the capacity auction. We assume that there is a bid cap in the capacity auction, which is common to all bidders and set to $140 \mathrm{EUR} / \mathrm{kW}$ as a baseline. This is approximately 1.5 times the net cost of new entry (net CONE), accounting for electricity market and ancillary market revenues. This kind of multiplier is used in several capacity markets, including in the British capacity auction. We use 500 EUR as the strike price used for the RO difference payment, given that this value is often mentioned in the I-SEM consultation documents.

New entry. Our entry modeling has four key features. First, we consider a range of volumes up to $3 \mathrm{GW}$, reflecting uncertainty over how much new entry will occur. Second, we choose the technologies of entering units to approximate the existing (non-renewable) capacity mix. Third, the ownership of new units is dispersed to ensure that entry makes the market less concentrated (at a similar fuel mix). Fourth, similar to other non-ESB players, new firms behave competitively in the capacity market-but may have a degree of market power in the electricity market. Specifically, we assume that five new firms own all potential new generating units. Three own a gas-fired unit with $300 \mathrm{MW}$ of nominal capacity, one owns an oil unit (200 MW), and one owns a distillate unit (60 MW); the combined capacity is $1160 \mathrm{MW}$ or $1082 \mathrm{MW}$ after derating, i.e., approximately $1 \mathrm{GW}$. We also consider twice these entry volumes (e.g., one firm now owns two 300 MW gas units, etc.) - although $1 \mathrm{GW}$ new entry is the most plausible scenario in the short term.

We take the new units' availabilities and de-rating factors to be the same as for incumbent units; their fixed costs are higher due to investment costs. ${ }^{36}$ We use the marginalcost curve made up of incumbent units of the same fuel type to derive a representative efficiency level for the new firms. ${ }^{37}$

some adjustments to capacity figures to put them back on a like-for-like basis.

${ }^{36}$ We take these from SEM-12-078.

${ }^{37}$ To illustrate, consider a case with three new gas units. We construct a cost curve for incumbent gas units by sorting them in increasing order of their marginal costs, and then fit a polynomial function to smoothen this curve. To obtain a representative efficiency level for the three units, we give one the minimum, one the median, and one the maximum marginal cost. More generally, with $m$ new units, we use the same procedure to space them evenly along the constructed cost curve. 


\section{Analytical benchmarks}

\subsection{Energy-only market}

Our first benchmark is an "energy-only" market that operates without any capacity mechanism. Firms then receive revenue only from the electricity market. Several generation units in the SEM are rarely needed to meet total demand, and these unprofitable units now exit the market one by one. This continues until the marginal unit can just cover its costs (also raising the profits of remaining incumbent units). Simulations show that of the original 41 units, 13 units are left in the energy-only market in a less competitive market (0-60\% forward contract share); this corresponds to $3971 \mathrm{MW}$ of existing capacity exiting. With a more competitive electricity market, total revenues (buyer costs) falland only 12 units ( $80 \%$ forward contracts) or 11 units ( $100 \%$ forward contracts) stay in the market. The earliest exits include those of high-cost oil and distillate units owned by SSE and AES.

The highest prices in the energy-only market occur for two reasons: firms withhold generation or demand exceeds total capacity. In a more competitive market, more highcost units exit; this reduces the average price (over the year) - but it also means that demand exceeds capacity in more individual hours, so that the maximum market price can rise in such times. Figure 1 shows price duration curves. With a fully competitive market, firms' stepwise marginal cost functions are tracked exactly, leading to jumps in the price duration curve. Reduced competitiveness shifts the curves outward, especially during high-price hours. This is driven by changes in the strategic players' generation volumes, with ESB reducing its generation most strongly. NIE PP also withholds output as it benefits disproportionately from the exit of several units of similarly-sized rivals SSE and AES.

In sum, an energy-only market entails significant exit of existing small high-cost units - together with the possibility of significant strategic behaviour by large players.

\subsection{Capacity market with competitive bidding}

Our second benchmark introduces a capacity market in which all firms behave competitively. A competitive bid is equal to the amount that a generating unit needs to break even in the long term. In general, it will depend on (i) the total generation portfolio in the market, and (ii) the competitiveness of the electricity market. 
Figure 1: Price duration curves in an energy-only market (for different shares of forward contracting).

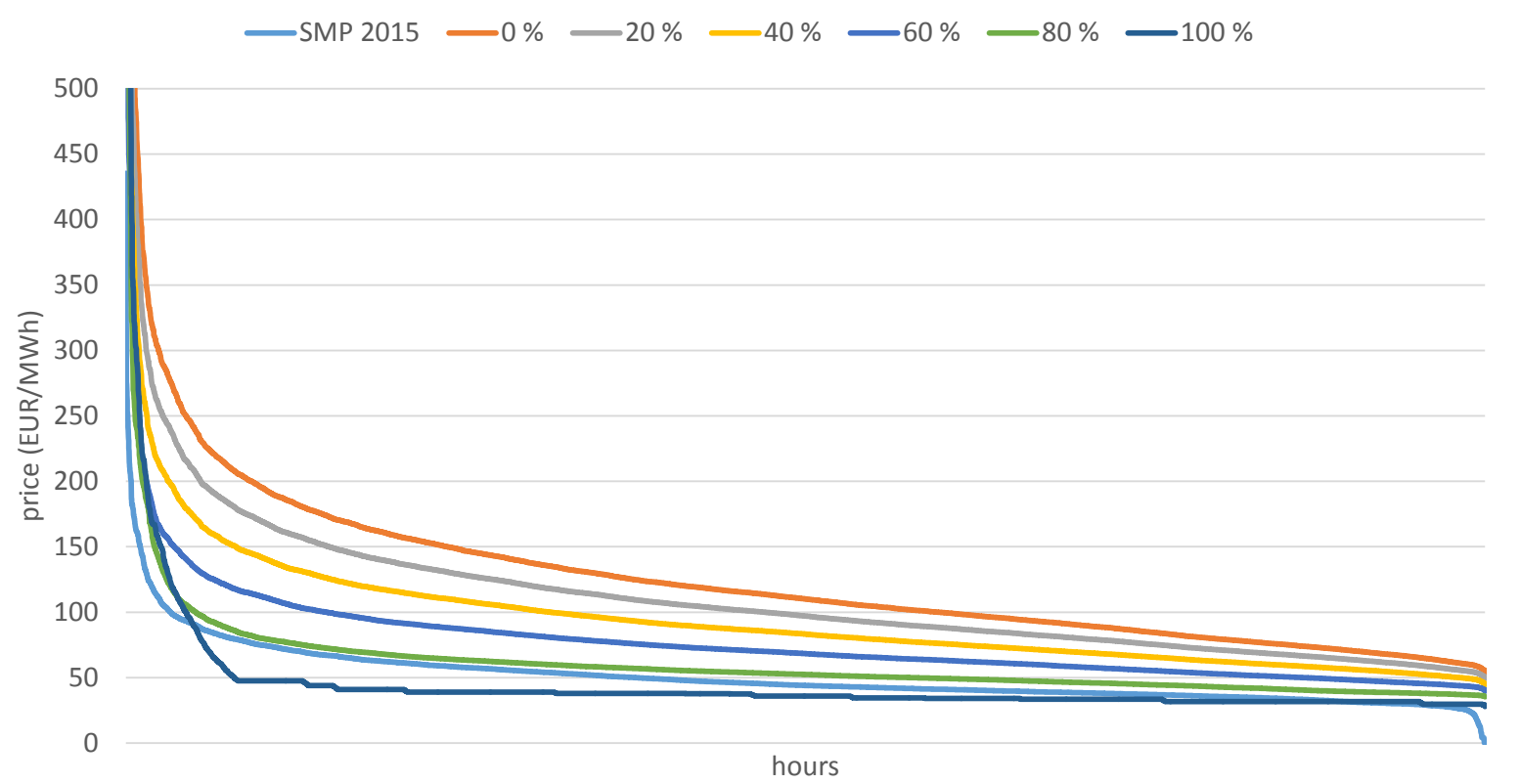

Figure 2 shows two simulated aggregate supply curves in the capacity market. These are constructed by showing the bids of existing units in increasing order, and illustrate the competitive clearing price in the capacity market, given a particular volume of procured capacity. Units with low marginal cost run most of the time and are profitable without any capacity payment, so their competitive bids in the capacity auction are zero. Other units bid between zero and their fixed cost depending on how much of their fixed cost they can cover with profits from the electricity market. Competitive bids are generally higher if the electricity market is fully competitive (solid blue line, $100 \%$ forwards) than if it is not very competitive (dashed red line, $0 \%$ forwards). Intuitively, firms then make less revenue in the electricity market so need more of a "top up" from the capacity market.

The bids of ESB's three coal units illustrate the effects of ownership. These are marginal units with higher marginal costs than its gas-fired units. With less competition in the electricity market, ESB uses only its gas units. Therefore its coal units have to bid their fixed costs to break even (dashed red line), which are considerably higher than the gas units' fixed costs of around $60 \mathrm{EUR} / \mathrm{kW}$ (accounting for de-rating). By contrast, with a competitive electricity market, all firms' generation volumes are higher; this raises the profits of ESB's coal units and allows them to bid lower in the capacity 
Figure 2: Capacity market with competitive bidding (for different shares of forward contracting).

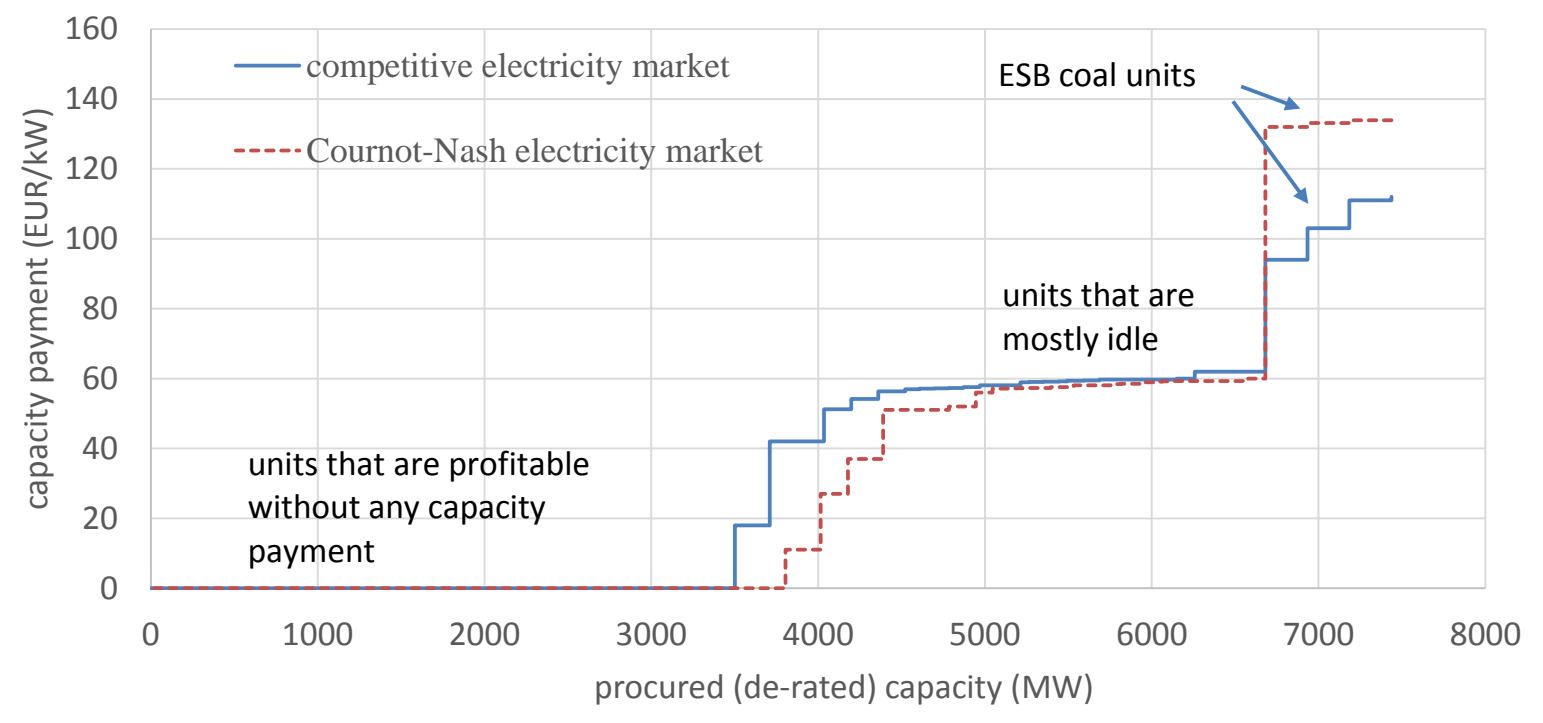

market. It also interesting to contrast ESB's bidding behaviour with its smaller rival AES. AES similarly owns coal-fired plants but these have the lowest costs within its generation portfolio. These are always used and profitable - and hence always bid zero in the capacity market.

In sum, relative to the energy-only market, the introduction of a competitive capacity market tends to induce ESB to make more use of its coal-fired generation by allowing it to cover their fixed costs. In the subsequent sections, we use competitive bidding as the benchmark to measure strategic behaviour, the cost of which can be calculated as the deviation from the competitive least-cost outcome.

\section{Impacts of strategic behaviour}

We next present baseline simulation results for the capacity market with strategic behaviour, where participation is limited to incumbents. We then examine the impacts of new entry, and quantify the total cost of strategic behaviour across a range of scenarios. 


\subsection{Strategic behaviour without new entry}

Figure 3 displays the competitive benchmark for the capacity auction against simulated clearing prices if ESB can bid strategically. Both are derived assuming a competitive electricity market (with 100\% forward contracts). This illustrates how ESB (i) would pursue different bidding strategies depending on the total volume of capacity procured, and (ii) can exert market power via the capacity market even if the electricity market is competitive.

First, if $4500 \mathrm{MW}$ or less capacity is procured, ESB submits bids at below-competitive prices for some of its units. This forces some of its rivals' units out of the market-so that ESB then owns over half of the units active in the electricity market. Such predatory pricing in the capacity auction affords ESB higher profits in the electricity market, and these outweigh the lower capacity payments. Second, if $4750 \mathrm{MW}$ or more capacity is procured, ESB submits the highest-possible bid for as many units as needed to ensure that one sets the clearing price at the $140 \mathrm{EUR} / \mathrm{kW}$ bid cap. ${ }^{38}$ This compares with a competitive price of around $60 \mathrm{EUR} / \mathrm{kW}$, which would just cover the fixed costs of ESB's mostly-idle gas units. ESB here gains by sacrificing these gas units in the auction and instead getting the maximum price for its remaining units (which is profitable even if only few units remain active).

ESB is said to be "pivotal" when its capacity is necessary to achieve the desired level of capacity; this region is shown to the right of the vertical green dashed line in Figure 3. In such situations, ESB can directly take actions that set the clearing price in the capacity auction at the bid cap. However, note also that ESB can still wish to engage in predation if it is not pivotal, for instance where $4750 \mathrm{MW}$ is procured.

ESB's strategic behaviour in the capacity market also depends on the competitiveness of the electricity market. For weaker competition, with $80 \%$ or less forward contracts, predatory pricing ceases to be beneficial where procured capacity is less than $4500 \mathrm{MW}$; instead, ESB bids competitively with all units. In such cases, a more competitive electricity market again means a less competitive capacity market, as small changes in capacitymarket bids can then have a larger effect on the resulting active generation portfolio.

\footnotetext{
${ }^{38}$ We analyze in Section 7.2 the impacts of setting a lower bid cap for incumbents. See also SEM-16010 (Section 4.7) for discussion of other practical measures to control market power, including: making bidding mandatory for all generators (to prevent withholding of individual units), not allowing units that fail to participate in a capacity auction to participate in subsequent auctions, not allowing large incumbents to act as aggregators for small third-party bidders, designing suitable rules on information sharing as well as pro-active market monitoring.
} 
Figure 3: Capacity market with strategic behaviour (competitive electricity market, no new entry).

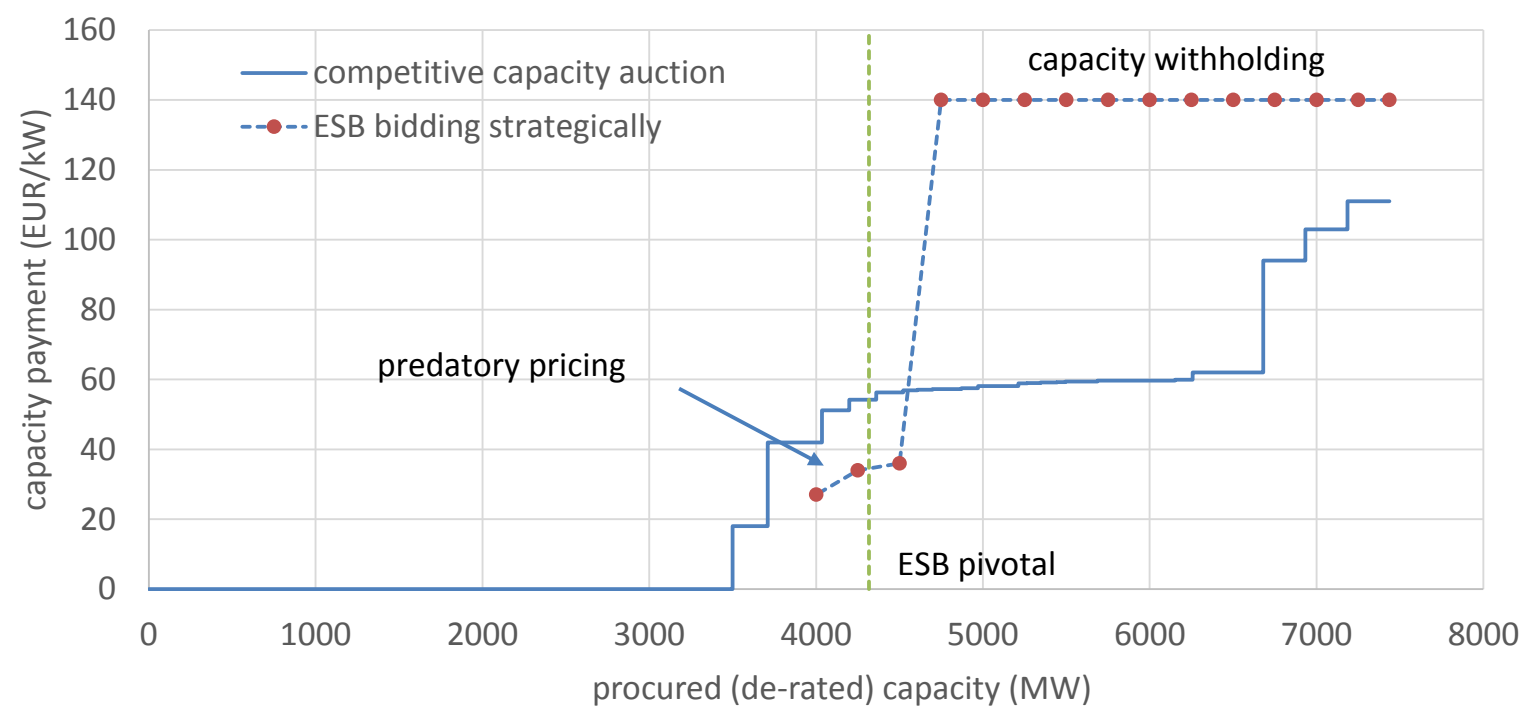

Loosely speaking, this raises the potential returns to strategic behaviour.

As discussed in Section 4, the amount of procured capacity in the future I-SEM is likely to lie between 5500-7000 MW. Figure 3 shows that, with 100\% forward contracting, ESB's preferred strategy in this range is capacity withholding. Our simulations confirm that this finding is robust across all degrees of electricity-market competitiveness (from zero up to $100 \%$ forward sales).

\subsection{Strategic behaviour with potential new entry}

Apart from security supply from existing generation, a capacity market can also attract new entrants. We here study several scenarios in which new firms bid in the capacity auction, and then build new generating units if they win. Like incumbents other than ESB, potential entrants may have a degree of market power in the electricity market but bid competitively in the capacity market.

Figure 4 illustrates clearing prices in the capacity market when the electricity market is fully competitive and there are five new firms with $1082 \mathrm{MW}$ of potential new capacity. With no supra-competitive mark-ups in the electricity market, new units have to submit relatively high bids in the capacity auction to be able to cover their costs. Consequently, a capacity-withholding strategy is not as profitable for ESB as aggressively as in the 
no-entry case. For example, with procured capacity of 6000-6500 MW, ESB bids just low enough to keep four new potential entrants out of the market. The less capacity is procured the more new units ESB wants to keep out. By contrast, if $6750 \mathrm{MW}$ or more capacity is procured, then ESB accommodates all entry and withholds capacity such that the clearing price is equal to the bid cap.

In Figure 5, there is again 1082 MW of new capacity-but now there are high markups in the electricity market (with $0 \%$ forward contracts). Therefore, new entrants now submit very low bids in the capacity auction, with most units bidding zero. For ESB, this means that some of its units may be displaced by new entrants and it can exert less market power than in the case without new entry (see Figure 3). For example, with $6250 \mathrm{MW}$ or more procured capacity, entrants displace ESB's low-cost capacity, pushing the competitive benchmark to the right while ESB's strategy relative to the competitive benchmark stays approximately the same. However, ESB can still set the clearing price at the bid cap across a significant range of volumes of procured capacity. Intermediate degrees of competitiveness in the electricity market (between 0\% and 100\% forward contracts) yield outcomes that lie between the two extremes of Figures 4 and $5 .^{39}$

In sum, new entry constrains ESB's strategic behaviour to some extent, depending on how competitive the electricity market is and how close different potential entrants' bids are to the clearing price in the capacity auction.

\subsection{Total costs of strategic behaviour}

Table 2 summarizes outcomes across different "market designs" in our baseline scenario (6000 MW, 80\% forwards). Relative to an energy-only market, the introduction of a competitive capacity market $(\mathrm{CM})$ raises number of active units from 12 to over 30 (resulting in much higher fixed costs); this prevents the electricity price from exceeding $500 \mathrm{EUR} / \mathrm{MWh}$ and reduces the average price as well as buyer costs in the electricity market by around $10 \%$. Relative to this competitive benchmark, strategic behaviour in the capacity market (CM0, CM1, CM2) leaves the number of active units mostly unchanged; any new entrants replace less efficient incumbents and further reduce the electricity price.

The key finding of this paper is that strategic behaviour in the capacity auction

\footnotetext{
${ }^{39}$ In our model, new entry occurs only via the capacity auction; more generally, these new entrants might also enter an energy-only market. Our focus is on the costs of strategic behaviour in the capacity market (relative to competitive bidding) rather than the comparison between a capacity-market design and the energy-only market.
} 
Figure 4: Capacity market with strategic behaviour (competitive electricity market, 1 GW new entry).

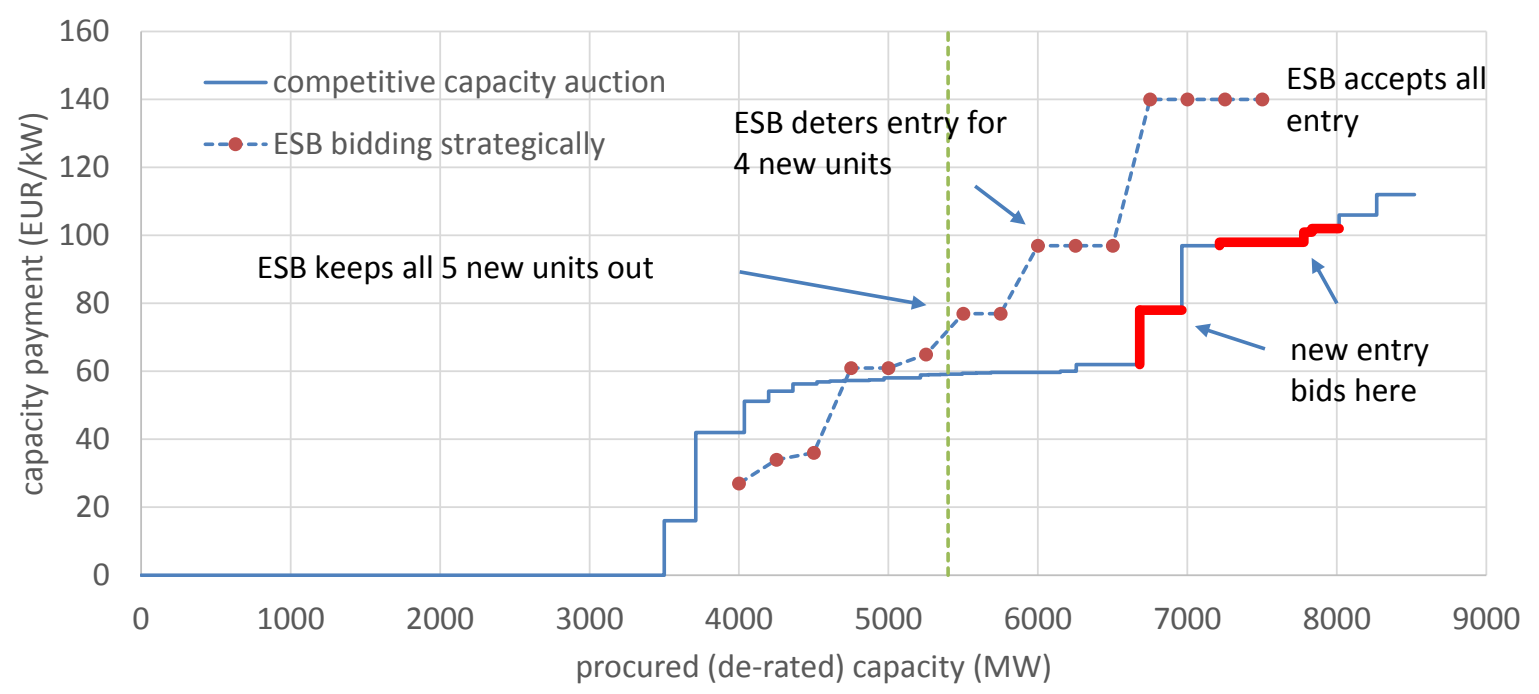

significantly raises total buyer costs. Depending on the amount of entry, the clearing price for procuring $6000 \mathrm{MW}$ rises from 59 EUR to 89-140 EUR and total buyer costs in the capacity market rise by 175-480 mEUR (or 50-136\%). Lower buyer costs in the electricity market are outweighed by the direct effect of higher buyer costs in the capacity auction itself: the combined costs to buyers rise by $2-29 \%{ }^{40}$

Table 3 illustrates the impacts on total buyer costs of varying (i) the volume of procured capacity and (ii) the competitiveness of the electricity market (for a scenario with 1 GW new entry). First, a higher procured capacity raises total buyer costs in the capacity auction, even with competitive bidding; Table 3 shows how it typically also raises the costs of market power as ESB becomes relatively more pivotal. Moreover, our simulations suggest that higher procured capacity has little knock-on impact on total buyer costs in the electricity market. Second, as already suggested by Figures 4 and 5, the interaction with the competitiveness of the electricity market can depend on the fine details of the auction. ${ }^{41}$ For procured capacity of $6000 \mathrm{MW}$, a more competitive electricity

\footnotetext{
${ }^{40}$ The RO design does not meaningfully limit market power in these scenarios: the capacity market pushes the maximum electricity price down to $362 \mathrm{EUR} / \mathrm{MWh}$, so the RO strike price of $500 \mathrm{EUR} / \mathrm{MWh}$ never actually binds. See Appendix B for further analysis on the impacts of setting a lower RO strike price.

${ }^{41}$ The two columns with forward contracts of $100 \%$ and $0 \%$ correspond, respectively, to outcomes with different procured capacities as per Figures 4 and 5. For example, in Figure 4, procured capacity of 7000 $\mathrm{MW}$ is achieved at a clearing price of $140 \mathrm{EUR} / \mathrm{kW}$ : hence the increase in total buyer costs relative to
} 
Figure 5: Capacity market with strategic behaviour (Cournot-Nash electricity market, 1 GW new entry)

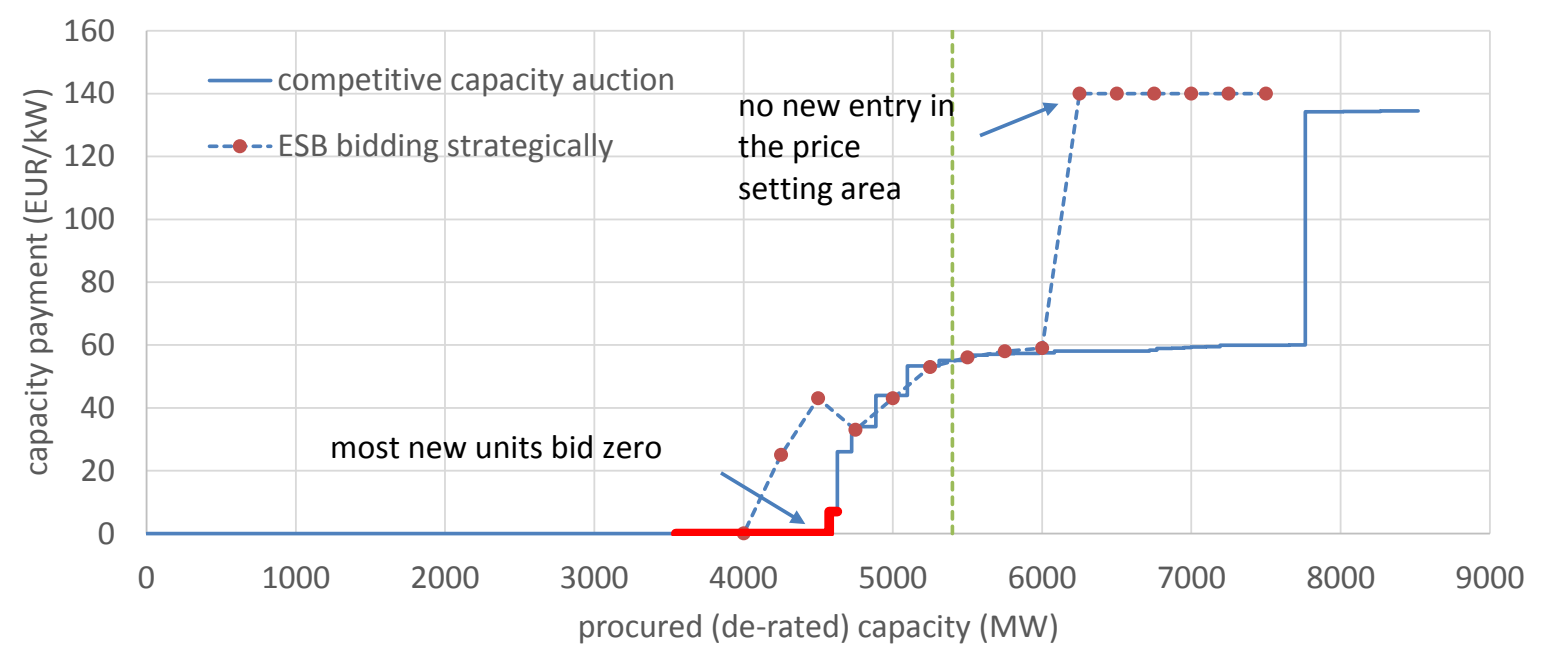

market tends to increase the impact of strategic behaviour on buyer costs in the capacity market; the additional buyer costs are up to $230 \mathrm{mEUR}$ (or around 60\%) across a range of scenarios. However, with low procurement of $5000 \mathrm{MW}$ and $60 \%$ forward contracting, strategic behaviour in the capacity auction decreases buyer costs - this is an instance of predatory pricing (similar to Figure 3 above).

In sum, for plausible scenarios with around 6000 MW procured capacity, 60-80\% forward contracting, and up to $1 \mathrm{GW}$ new entry, our simulations suggest that strategic behaviour raises buyer costs in the capacity auction by around 150-400 mEUR (40-100\%) above the competitive least-cost solution. This translates into an increase of around $10-25 \%$ in buyer costs across the electricity and capacity markets, and suggests that policymakers' concerns about market power are well-founded.

\section{Measuring and mitigating market power}

In this section, we assess a widely-used ex ante screening tool for market power, and then examine several auction designs to mitigate market power.

the competitive benchmark equals $(140 \mathrm{EUR} / \mathrm{kW}-97 \mathrm{EUR} / \mathrm{kW}) \times 7000 \mathrm{MW}=301 \mathrm{mEUR}$. 
Table 2: Outcomes under different "market designs" (electricity market with $80 \%$ forward contracting, capacity market with $6000 \mathrm{MW}$ procured capacity).

\begin{tabular}{lccccc}
\hline Market design & Energy-only & CM & CM0 & CM1 & CM2 \\
\hline Total buyer costs, electricity market (mEUR) & 1406.5 & 1285.7 & 1285.7 & 1161.8 & 1138.4 \\
Total buyer costs, capacity market (mEUR) & - & 351.9 & 831.7 & 575.0 & 527.6 \\
Weighted average electricity price (EUR/MWh) & 66.1 & 60.2 & 60.2 & 54.0 & 52.8 \\
Maximum electricity price (EUR/MWh) & 1632.9 & 361.6 & 361.6 & 298.1 & 274.8 \\
Hours when price > 500 EUR/MWh & 21 & 0 & 0 & 0 & 0 \\
Total variable costs (mEUR) & 623.4 & 626.8 & 626.8 & 639.7 & 628.6 \\
Total fixed costs (mEUR) & 248.2 & 385.0 & 385.2 & 416.5 & 416.5 \\
Capacity auction clearing price & - & 59 & 140 & 97 & 89 \\
Number of active generating units & 12 & 32 & 31 & 32 & 32 \\
Active nominal capacity (MW) & 3988 & 5965 & 5941 & 5928 & 5928 \\
\hline
\end{tabular}

$C M=$ competitive capacity market, CM0 = strategic capacity market without entry, CM1 = strategic capacity market with $1 G W$ entry, CM2 = strategic capacity market with $2 G W$ entry

Table 3: Increase in total buyer costs in the capacity market due to strategic behaviour: (with $1 \mathrm{GW}$ entry, varying procured capacity and competitiveness of electricity market).

\begin{tabular}{lcccc}
\hline Forward contracts & $\mathbf{1 0 0 \%}$ & $\mathbf{8 0 \%}$ & $\mathbf{6 0 \%}$ & $\mathbf{0 \%}$ \\
\hline $5000 \mathrm{MW}$ & $15[5 \%]$ & $11[4 \%]$ & $-11[-4 \%]$ & $0[0 \%]$ \\
$6000 \mathrm{MW}$ & $224[62 \%]$ & $227[64 \%]$ & $151[44 \%]$ & $9[3 \%]$ \\
$7000 \mathrm{MW}$ & $301[44 \%]$ & $560[133 \%]$ & $561[134 \%]$ & $564[136 \%]$ \\
$8000 \mathrm{MW}$ & $304[37 \%]$ & $48[4 \%]$ & $46[4 \%]$ & $46[4 \%]$ \\
\hline
\end{tabular}

\subsection{Measurement: Residual Supply Index}

The "Residual Supply Index" (RSI) is often used in antitrust analysis to measure a firm's ability to exercise market power. The RSI for ESB in the capacity market is calculated as $\mathrm{RSI}_{\mathrm{ESB}}=$ (total capacity - ESB capacity) / (procured capacity), where "total capacity" includes all pre-existing capacity as well as any capacity of potential entrants. Smaller RSI values should indicate that the firm can exercise more market power, given that it is larger relative to the market overall. If its RSI is less than 100\%, then ESB is pivotal because its capacity is then necessary to meet the target procured capacity. Often, an RSI of at least 110-120\% for each firm in a market is seen as desirable. ${ }^{42}$

We compare the RSI with the Lerner index for ESB, which measures the share of its "mark-up" in the capacity payment. ${ }^{43}$ A negative correlation with the RSI is expected given that a higher Lerner index signifies greater market power. Figure 6 plots these for three different amounts of procured capacity, assuming throughout an $80 \%$ forward

\footnotetext{
${ }^{42}$ See e.g. Twomey et al. (2006).

${ }^{43}$ Lerner index is the price mark-up in the market divided by the total payment. It varies from $0 \%$ (fully competitive market) to $100 \%$ (price consists of mark-up only).
} 
contract share in the electricity market. ${ }^{44}$ The correlation between the RSI and the Lerner index is -0.218 : negative but not very pronounced. The three left-most points on each curve, with very low Lerner index values, reflect the clearing price being set by ESB's high-cost/low-margin coal units. Conversely, there are several scenarios with large mark-ups even where ESB's RSI exceeds 110\%. Figure 6 also captures how additional entry affects ESB's market power. While new entry raises ESB's RSI (by construction), it appears to shift the Lerner-index curve rightwards more than it pushes it downwards. Even with considerable new entry, entrants' bids may be in such a narrow price range that incumbent firms can still exercise market power. This reflects that fixed costs do not vary much between (hypothetical) new units, and are higher than for existing units.

In sum, the RSI is an imperfect indicator in this application. It seems to work relatively better with little new entry into the market - but a "high" RSI above $110 \%$ may not be a reliable signal for "low" market power, especially in conjunction with new entry. $^{45}$

\subsection{Mitigation: Lower bid cap for incumbent units}

One policy option to limit the exercise of market power is to set a lower bid cap for incumbent generating units than for new entrants. This approach has been used, for example, in the British capacity auction design; see also the suggestions in Cramton and Stoft (2008). The objective is to ensure that new entrants set the clearing price; the approach has obvious appeal if new entrants do indeed bid competitively and procured capacity exceeds existing capacity. A drawback is that, with excess capacity, the lower bid cap will often bind, implying that the regulator effectively chooses the clearing price; this runs against the spirit of using a market mechanism in the first place.

Figure 7 shows results for a scenario in which incumbent units can bid at most 60 $\mathrm{EUR} / \mathrm{kW}$ while potential entrants have the previous bid cap of $140 \mathrm{EUR} / \mathrm{kW} .{ }^{46}$ The

\footnotetext{
${ }^{44}$ Each point in the graph corresponds to a specific amount of procured capacity. Procured capacity starts from $5000 \mathrm{MW}$ on the right-hand side of each curve and increases to the left with $250 \mathrm{MW}$ increments. By definition, RSI increases when there is more entry and the procured capacity stays the same.

${ }^{45}$ Two other familiar measures of potential market power are similarly imperfect. First, the Pivotal Supplier Indicator (PSI) is a special case of the RSI: PSI $=1$ if $\mathrm{RSI}<100 \%$ and $\mathrm{PSI}=0$ otherwise; it is clear that ESB's market power can be significant even where its PSI=0. Second, the Irish electricity market is highly concentrated with a Herfindahl index (HHI) of 2468; 2 GW new entry pushes this down to 1691 but again Figure 6 shows that this can still be consistent with significant market power in the capacity auction.

${ }^{46}$ The lower bid cap is approximately $65 \%$ of estimated net CONE in Ireland (91.88 EUR).
} 
Figure 6: Measuring market power in the capacity market using the Residual Supply Index (for different procured capacity volumes, $80 \%$ forward contracting).

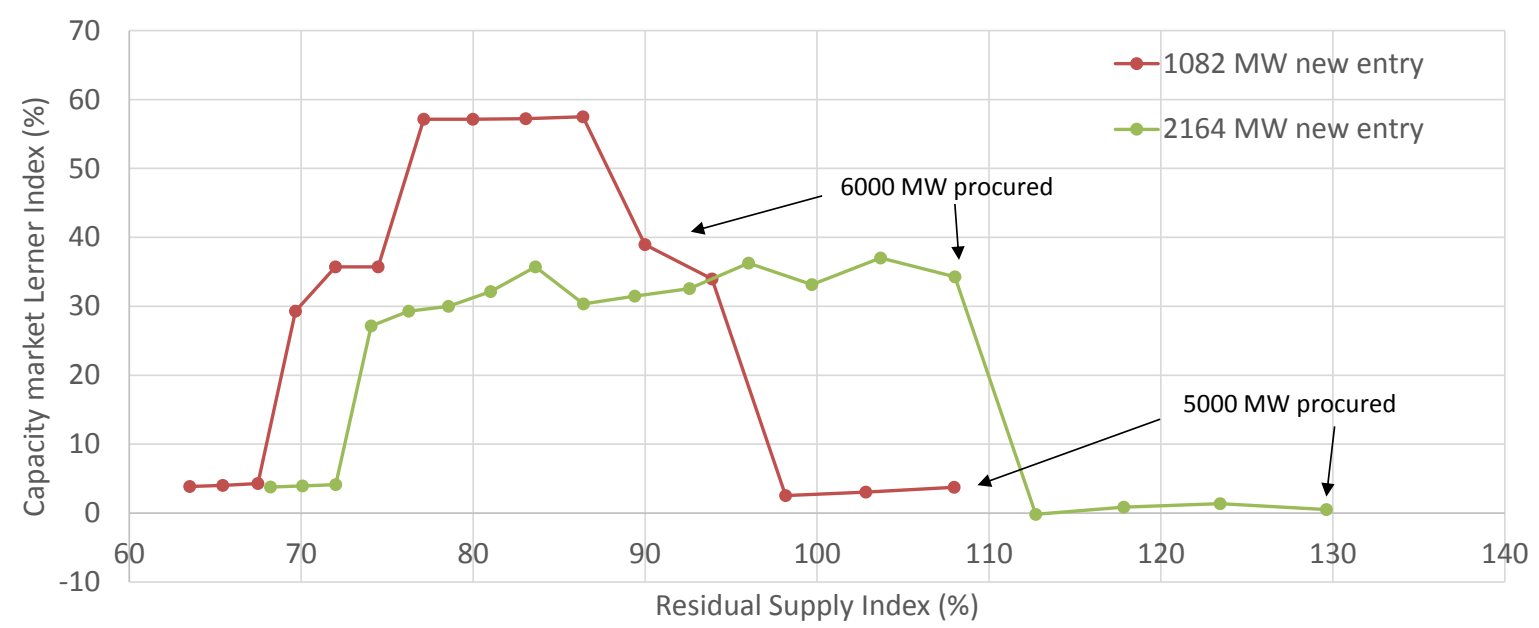

electricity market is perfectly competitive (100\% forward contracts) and there is $1 \mathrm{GW}$ of entry. We find that, as long as existing capacity (6681 MW) falls short of procured capacity, this yields a competitive clearing price in the capacity auction. If $4750-6500$ MW is procured the lower bid cap is binding. With a less competitive electricity market, some new entrants bid below the incumbents' bid cap; ESB then sets a strategic price at the level of this lower bid cap. More generally, less competition in the electricity market increases the range of outcomes in which the lower bid cap is binding.

In sum, these results suggest that a bid cap can partially help to mitigate strategic behaviour but its implementation will depend on the regulator having a sufficiently detailed understanding of the market environment. Bids caps will tend to be more effective where the electricity market is already relatively more competitive. ${ }^{47}$

\section{Conclusion}

The use of capacity mechanisms is growing as electricity markets around the world are being re-designed to cope with the challenges posed by the energy transition. Policymakers are already concerned about the potential for strategic behaviour by firms in capacity

\footnotetext{
${ }^{47}$ Similarly, using a downward-sloping demand curve can, at least in some cases, mitigate market power in the capacity auction - though we find that it needs to be well-coordinated with bid-cap setting. See Appendix $\mathrm{C}$ for further details.
} 
Figure 7: Capacity market with a lower bid cap for incumbents (competitive electricity market, 1 GW new entry).

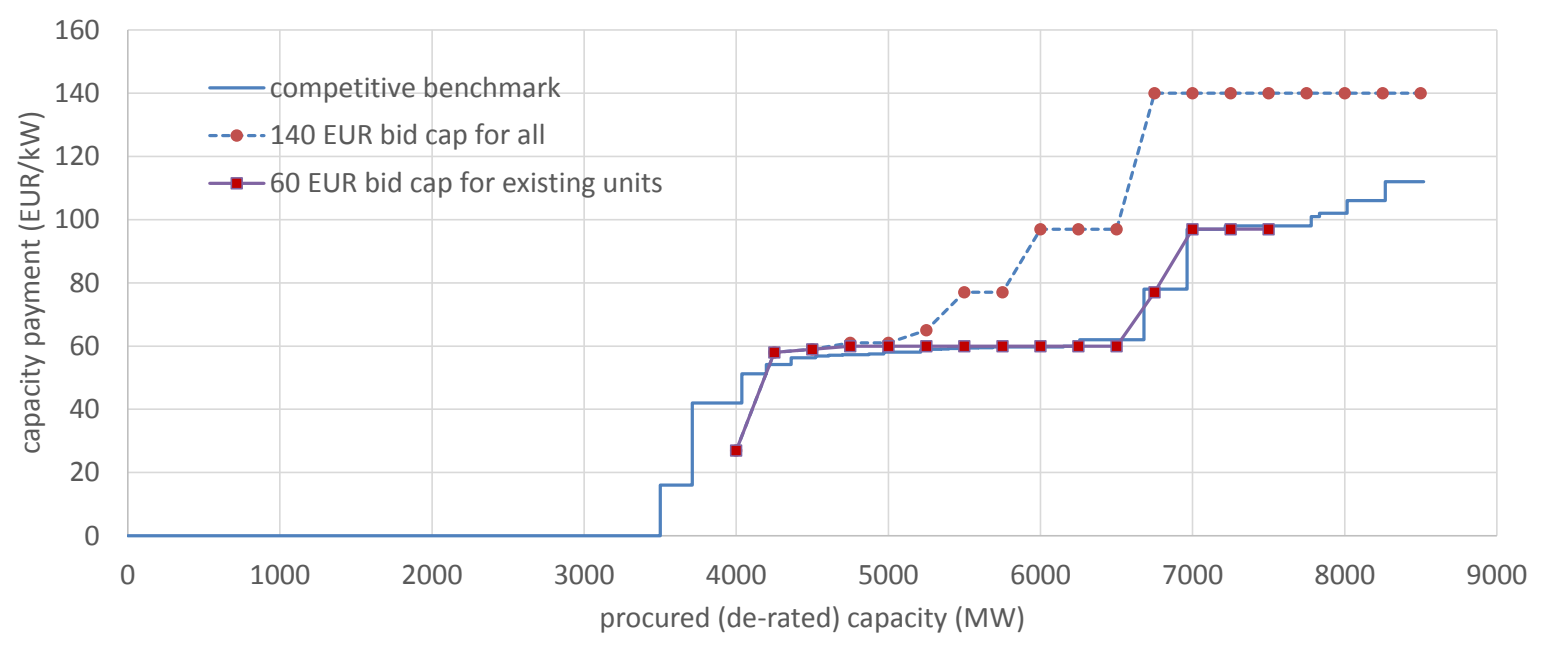

auctions but the literature has so far contributed only little to this topic. This paper has presented a new model of market power across both the electricity market and capacity auction together with ex ante simulation results for the new Irish I-SEM design.

We leave important issues to future research: (1) extending our model implementation to multiple strategic players in the capacity auction; (2) examining how the introduction of a capacity market interacts with firm behaviour in balancing and forward markets; (3) incorporating the increasing roles of battery storage and demand-side aggregation; (4) considering the overall welfare impacts of strategic behaviour, including its environmental impacts.

\section{Acknowledgements}

We are grateful to three referees for detailed feedback and suggestions, to Anette Boom and David Newbery for advice, and to participants of EPRG seminars at Cambridge University for helpful comments. This study is funded by the Fortum Foundation and the Strategic Research Council, Finland, Project No. 292854. This paper is a revised version of Teirilä's EPRG Working Paper 1712. All views expressed and any remaining errors are ours. 


\section{References}

Allaz, B. and J. -L Vila. (1993). "Cournot Competition, Forward Markets and Efficiency" Journal of Economic Theory, 59(1):1-16.

Anderson, E. J., X. Hu and D. Winchester. (2007). "Forward Contracts in Electricity Markets: The Australian Experience" Energy Policy, 35(5):3089-3103.

Baldick, R. and W. Hogan (2002). "Capacity Constrained Supply Function Equilibrium Models of Electricity Markets: Stability, Non-decreasing Constraints, and Function Space Iterations" POWER Working Paper PWP-089, University of California Energy Institute.

Bidwell, M. (2005). "Reliability Options: A Market-Oriented Approach to Long-Term Adequacy" Electricity Journal, 18(5):11-25.

Borenstein, S., J. B. Bushnell and F. A. Wolak (2002). "Measuring Market Inefficiencies in California's Restructured Wholesale Electricity Market" American Economic Review, 92(5):1376-1405.

Buehler, S., A. Burger and R. Ferstl (2010). "The Investment Effects of Price Caps Under Imperfect Competition: A Note" Economics Letters, 106(2):92-94.

Bushnell, J. B., E. T. Mansur and C. Saravia (2008). "Vertical Arrangements, Market Structure, and Competition: An Analysis of Restructured US Electricity Markets" American Economic Review, 98(1):237-266.

Chao, H. and R. Wilson (2004). "Resource Adequacy and Market Power Mitigation via Option Contracts" Electric Power Research Institute and Stanford University.

Cramton, P., A. Ockenfels and S. Stoft (2013). "Capacity Market Fundamentals" Economics of Energy \& Environmental Policy, 2(2):27-46.

Cramton, P. and S. Stoft (2006). "The Convergence of Market Designs for Adequate Generating Capacity." White paper, California Electricity Oversight Board.

Cramton, P. and S. Stoft (2008). "Forward Reliability Markets: Less Risk, Less Market Power, More Efficiency" Utilities Policy, 16(3):194-201. 
de Vries, L. (2004). "Securing the Public Interest in Electricity Generation Markets, The Myths of the Invisible Hand and the Copper Plate." PhD Thesis, Delft University.

di Cosmo, V. and M. Á. Lynch (2015). "The Irish Electricity Market: New Regulation to Preserve Competition" ESRI Research Note, Economics and Social Research Institute (ESRI), Dublin.

ECA (2015). "European Electricity Forward Markets and Hedging Products: State of Play and Elements for Monitoring" Report prepared for the Agency for the Cooperation of Energy Regulators, September 2015. http://www.acer.europa.eu/ en/Electricity/Market\%20monitoring/Documents_Public/ECA\%20Report\%20on\% 20European\%20Electricity $\backslash \% 20$ Forward\%20Markets.pdf.

Einav, L. (2010). "Not All Rivals Look Alike: Estimating an Equilibrium Model of the Release Date Timing Game" Economic Inquiry, 48(2):369-390.

Finon, D. and V. Pignon (2008). "Electricity and Long-Term Capacity Adequacy: The Quest for Regulatory Mechanism Compatible with Electricity Market" Utilities Policy, 16(3):143-158.

Green, R. J. and D. M. Newbery (1992). "Competition in the British Electricity Spot Market" Journal of Political Economy, 100(5):929-953.

Hogan, W. W. (2005). "On an "Energy Only" Electricity Market Design for Resource Adequacy." Mimeo, Harvard University.

Hortaçsu, A. and S. L. Puller (2008). "Understanding Strategic Bidding in Multi-unit Auctions: A Case Study of the Texas Electricity Spot Market" RAND Journal of Economics, 39(1):86-114.

IEA (2016). "Re-Powering Markets: Market Design and Regulation During the Transition to Low-Carbon Power Systems" Paris, France: International Energy Agency.

Ito, K. and M. Reguant (2016). "Sequential Markets, Market Power and Arbitrage" American Economic Review, 106(7):1921-1957.

Joskow, P. L. (2007). "Competitive Electricity Markets and Investment in New Generating Capacity" The New Energy Paradigm, (D. Helm, ed.), Oxford University Press. 
Joskow, P. L. (2008). "Capacity Payments in Imperfect Electricity Markets: Need and Design." Utilities Policy, 16(3):159-170.

Joskow, P. L. and E. Kahn (2002). "A Quantitative Analysis of Pricing Behavior in California's Wholesale Electricity Market During Summer 2000" Energy Journal, 23(4):135 .

Léautier, T. -O.(2016). "The Visible Hand: Ensuring Optimal Investment in Electric Power Generation" Energy Journal, 37(2).

Mansur, E. T. (2008). "Measuring Welfare in Restructured Electricity Markets" Review of Economics and Statistics, 90(2):369-386.

Newbery, D. M. (1995). "Power Markets and Market Power" The Energy Journal, $16(3): 39-66$.

Newbery, D. M. (2016). "Missing Money and Missing Markets: Reliability, Capacity Auctions and Interconnectors" Energy Policy, 94:401-410.

Oren, S. S. (2005). "Generation Adequacy via Call Options Obligations: Safe Passage to the Promised Land" Electricity Journal, 18(9):28-42.

Puller, S. L. (2007). "Pricing and Firm Conduct in California's Deregulated Electricity Market" Review of Economics and Statistics, 89(1):75-87.

Ritz, R. A. (2016). "How Does Renewables Competition Affect Forward Contracting in Electricity Markets?" Economics Letters, 146:135-139.

Roques, F. A. (2008). "Market Design for Generation Adequacy: Healing Causes Rather Than Symptoms" Utilities Policy, 16(3):171-183.

Schwenen, S. (2014). "Market Design and Supply Security in Imperfect Power Markets" Energy Economics, 43:256-263.

Sweeting, A. (2007). "Market Power in the England and Wales Wholesale Electricity Market 1995-2000" Economic Journal, 117(520):654-685.

Teirilä, J. (2017). "Market Power in the Capacity Market? The Case of Ireland" EPRG Working Paper 1712, Cambridge University, July 2017. 
Twomey, P., R. Green, K. Neuhoff and D. Newbery (2006). "A Review of the Monitoring of Market Power, The Possible Roles of TSOs in Monitoring for Market Power Issues in Congested Transmission Systems" Cambridge Working Papers in Economics CWPE 0504, University of Cambridge.

Vázquez, C., M. Rivier and I. J. Pérez-Arriaga, (2002). "A Market Approach to LongTerm Security of Supply" IEEE Transactions on Power Systems, 17(2):349-357.

Willems, B., I. Rumiantseva and H. Weigt (2009). "Cournot versus Supply Functions: What Does the Data Tell Us?" Energy Economics, 31(1):38-47.

Wolfram, C. D. (1999). "Measuring Duopoly Power in the British Electricity Spot Market" American Economic Review, 89:805-826. 